\title{
Bio-Pesticide: A Clean Approach to Healthy Agriculture
}

\author{
Naveen Kumar Gautam ${ }^{*}$, Alok Kumar ${ }^{2}$ and V.K. Singh ${ }^{1}$ \\ ${ }^{1}$ Department of Agricultural Extension in C.S.A.U.A. \& T. Kanpur-208002, India \\ ${ }^{2}$ Department of Seed science and Technology in C.S.A.U.A. \& T. Kanpur-208002, India \\ *Corresponding author
}

A B S T R A C T

\begin{tabular}{|l|}
\hline Ke y w o r d s \\
Bio-pesticides, \\
$\begin{array}{l}\text { D.D.T., IPM, IAFP, } \\
\text { Food safety } \\
\text { conference }\end{array}$ \\
\hline Article Info \\
\hline $\begin{array}{l}\text { Accepted: } \\
\text { 04 February } 2018 \\
\text { Available Online: } \\
\text { 10 March } 2018\end{array}$ \\
\hline
\end{tabular}

Today, when we talk of agriculture, it is imperative to go to pesticides. There has been a constant change in the selection and use of pesticides by the time. For example, 4500 years ago Sumerian found evidence of the use of sulfur as a pesticide for agriculture. Mainly these were natural compounds, but after the Second World War a wave was used in the use of chemical pesticides, which has arsenic, hydrogen cyanide and D.D.T. like chemicals promoted. This study has been done in keeping in mind above facts to understand the awareness of farmers related to biological pesticides in the current scenario. As the current trend is moving towards organic food, the tendency has given new direction to the use, development and indispensability of biological pesticides and measuring this tendency is the primary goal of this study. To achieve this goal, we will need different types of information, for collecting this type of data we required various ways which are like interviews, questionnaires and surveys, observation, ethnographies, oral History, Case Studies, documents and records etc.

\section{Introduction}

We all know that agriculture is a business full of uncertainties, yet we get enough production in every area related to agriculture, because the agricultural conditions in our country are very good. An average of $15-25 \%$ of total agricultural production of the country is destroyed by pests, which is 1/4th of the country's annual production (2016). First, in India, the production of chemical pesticides started in 1951, due to the time and demand today it has become so much that India is at second place in the production of pesticides on the global plate and because average 18-26\% of the crop at the time of production and 5$13 \%$ of the crop after production is destroyed by insects for these reasons, the use and production of chemical pesticides has increased in India as well as in the entire world.

Food security has become an issue of awareness in the present. IAFP, Food Safety Conference and sixth national agrochemical conference are examples of global social awareness. Increasing food pollution is currently a matter of concern and it continues till the conservation of food from the production of the crop, because the chemical 
pesticides are used every phase to keep different insects away from different crops and this is the reason for the use of growing chemical pesticides annually.

\section{Why bio-pesticide?}

Deteriorating soil quality, poisonous soil water are the some side effects of indiscriminate use of chemicals in agriculture. Incresment in yield by chemicals can be recorded but in the case of quality this yield is less than the other and somewhere, the chemical components present in the crop make them even harmful to human health. We can understand the effects of these chemical pesticides on human health through many past and present events like that, according to recently released a report of W.H.O., the highest amount of D.D.T. has been found in indian women's brest milk. The next event is "the Supreme Court, on January $10 / 2017$, directed the Kerala government to pay Rs 500 crores in three months as compensation to over 5,000 victims of the use of endosulfan pesticide." Similarly, the side effects of chemical pesticides can be assessed across the country at different levels like Punjab and Haryana are an example in this case, most cancer patients in the country are in Punjab because they use the most chemical pesticides in the country in proportion to their area.

\section{Status of bio-pesticide in India}

At present, organic pesticides are only $4.2 \%$ of the entire pesticide market in India \& also CAGR is likely to increase by $20.2 \%$ from 2010 to 2020. In India, organic pesticides have been estimated to have market value of about 23.92 million USD (2015). Now the price of bio-pesticides has increased due to GST being implemented, government has fixed $18 \%$ GST on pesticides and bio-pesticides also fall in this category. In India, 12 types of bioinsecticides are registered under Insecticides Act, 1968 and there are about 150 biopesticide producing companies in India. Maharashtra is the most consuming state of bio-pesticide in India and Trichoderma viride, Pseudomonas fluorescens and Bacillus thuringiensis are the best-selling biopesticides in India.

India's Department of biotechnology provides cooperation in research and production of biopesticide, ICAR and DBT support 31 and 22 producer units, respectively. Bio-controle labs have been set up in different states of the country to promote bio pesticides.

\section{PESTICIDE CONSUMPTION OVER THE YEAR IN INDIA}

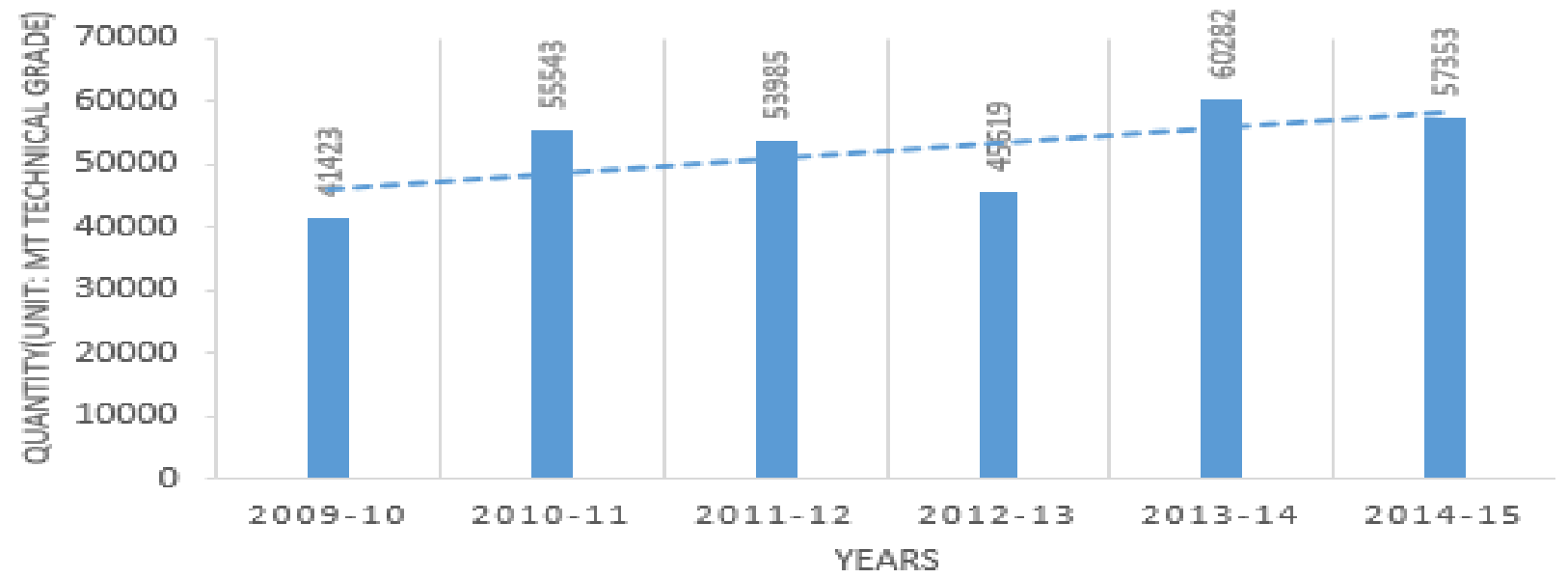

Source: Agrariancrisis.in \& pib.nic.in 


\section{Bio-pesticide}

\begin{tabular}{|l|l|c|c|}
\hline Sl. No. & State & Total pesticides consumed & Area $\left(\mathbf{k m}^{2}\right)$ \\
\hline $\mathbf{1}$ & Uttar-Pradesh & 39948 & 243,286 \\
\hline $\mathbf{2}$ & Punjab & 29235 & 50,362 \\
\hline $\mathbf{3}$ & Haryana & 21908 & 44,212 \\
\hline $\mathbf{4}$ & Maharashtra & 16480 & 307,713 \\
\hline $\mathbf{5}$ & Rajasthan & 15239 & 342,239 \\
\hline $\mathbf{6}$ & Gujrat & 13430 & 196,024 \\
\hline $\mathbf{7}$ & Tamil Nadu & 12851 & 130,060 \\
\hline
\end{tabular}

Source: Indiaforsafefoood.in

Status of bio-pesticide in India

\begin{tabular}{|l|l|}
\hline S. No. & Name of bio-pesticide \\
\hline 1 & Bacillus thuringiensis var. israelensis \\
\hline 2 & Bacillus thuringiensis var. kurstaki \\
\hline 3 & Bacillus thuringiensis var. galleriae \\
\hline 4 & Bacillus sphaericus \\
\hline 5 & Trichoderma viride \\
\hline 6 & Trichoderma harzianum \\
\hline 7 & Pseudomonas fluoresens \\
\hline 8 & Beauveriabassiana \\
\hline 9 & NPV of Helicoverpa armigera \\
\hline 10 & NPV of Spodoptera litura \\
\hline 11 & Neem based pesticides \\
\hline 12 & Cymbopogan \\
\hline
\end{tabular}

Source: DPPQ\&S Faridabad

\section{Challenges with bio-pesticides}

In present use of bio-pesticide is beneficial for society as well as for environment but it is also hard to promote. There are many reasons for this, as the market of chemical pesticides is off the peg and they are more easily found in almost every store than bio-pesticides, all the morechemical pesticides are cheaper than bio-pesticides and has more field efficiency.

In addition to this, the chemical pesticides' life spawn and target area is more than biopesticides. It is difficult to motivate the farmers for use of bio-pesticides due to above reasons.

\section{Efforts to promote organic pesticides}

To make the market accessible to biopesticides, the government should give different facilities to the manufacturers such as easier \& cheap registration process. For the farmers to move more and more organic farming, the government should give exemption to bio-pesticides and For the farmers to adopt it more and more, the government should use the mediums like K.V.K, K.C.C. and agri-clinic more effectively. Various awareness programs and occasional farmers' festivals can also be contributing in this. Awareness and interest of bio-pesticides can also be generated by 
farmers through RAWE, which is done by agricultural graduate students of universities and colleges, along with this, good research infrastructure, constructive support and policies can play vital role in the promotion of bio pesticides.

India has always been a country full of prospects for agriculture and farmers, where diversity occurs in our country's agriculture, there wide range of pests is also found, and we are dependent on various chemicals to keep them under control. But now Indian citizens have become aware of health and organic food and this awareness has given rise to the rapid demand of bio-pesticides. Now it is time that we must integrate our ancient knowledge with the new science, which will create awareness among the farmers for healthier and chemically free agriculture with the help of bio-pesticide.

\section{References}

"Bio pesticidea better alternative" 21 June 2015. The Hindu.

Chaudhry Malvika2016. Indian bio-pesticide market-current status and development trend, 5th CAC Asia Summit, 12-13th December 2016. Bangkok, Thailand

Menn, Julius J. "Biopesticides: Has their time come?" Journal of Environmental Science \& Health Part B 31.3 (1996): 383-389

Thakore Y. 2006. The bio pesticide market for global agricultural use. Industrial Biotechnology, Fall 2006: 194-208.

\section{How to cite this article:}

Naveen Kumar Gautam, Alok Kumar and Singh, V.K. 2018. Bio-Pesticide: A Clean Approach to Healthy Agriculture. Int.J.Curr.Microbiol.App.Sci. 7(03): 194-197. doi: https://doi.org/10.20546/ijcmas.2018.703.023 